\title{
O papel de transformação social da igreja angolana pós-guerra civil
}

The role of social transformation of the Angolan church after the civil war

José Afonso Sebastião*

Nelson Kilpp ${ }^{* *}$

\begin{abstract}
Resumo
O presente artigo tem como objetivo refletir sobre o papel da igreja angolana na transformação social do país em um contexto de pós-guerra civil (2002 ao atual momento). O conflito armado assolou o país por quase 30 anos. Em 1961, teve início a guerra de libertação colonial, que terminou em 1974. Na sequência, três movimentos entraram em choque pelo controle do país, dando início, assim, a uma terrível guerra civil que teve seu término em 2002. O artigo está dividido em 3 partes. Na primeira, apresentamos de maneira sucinta as raízes e as consequências do conflito armado e os desafios sociais no pós-guerra. Analisamos também a postura da igreja no período de guerra. Na segunda parte, falamos sobre o papel da igreja em um contexto de pós-guerra. Para tal, utilizamos o conceito de diaconia como ação transformadora, seu caráter prático e a relação existente entre diaconia, missão e ação social. Por fim, apresentamos a diaconia em Jesus, enfatizando dois aspectos: sua dimensão profética e curadora, no intuito de propor o papel da igreja angolana no pós-guerra.
\end{abstract}

\section{Palavras-chave \\ Clodovis Boff. Teologia Pública. Sentido da Vida. Espiritualidade. Ética.}

\begin{abstract}
This article wants to reflect on the role of the Church in Angola in a context of social changes after a period of civil war (after 2002). The military conflict devastated the country for almost 30 years. In 1961 started the war which led to the colonial independence in 1974. Thereafter three movements fought to gain the control of the country. This was the
\end{abstract}

[Texto recebido em setembro de 2016 e aceito em junho de 2017, com base na avaliação cega por pares realizada por pareceristas ad hoc]

* Graduando em Teologia (Faculdade Unida de Vitória). Graduando em Ciências da Computação (Universidade Claretiano). Graduando em Tecnologia de Redes de Computadores (Rede de Ensino Doctum). Membro do Núcleo de Estudos Protestantes da Cátedra Unida de Teologia Pública "João Dias de Araújo". É angolano e reside em Vitória/ES desde 2013. E-mail: alfaministro1@hotmail.com

** Doutor em Teologia. Professor de Teologia na Graduação na Faculdade e na Pós-Graduação (Faculdade Unida de Vitória). E-mail: nelson@faculdadeunida.com.br 


\begin{abstract}
beginning of a terrible civil war which only came to an end in 2002. The article has three parts: first it presents briefly the causes and consequences of the armed conflict and the social challenges of the post-war period. This part also includes the position of the Angolan Church during the war. The second part deals with the role of the Church in the post-war context. Here the idea of deaconship (diaconia) as a concrete transforming action and its relation with mission and social work was useful. The last part recalls the deaconship of Jesus and emphasizes its prophetic and the healing dimensions in order to design the role of the Angolan Church in the present post-war period.
\end{abstract}

\title{
Keywords
}

Church of Angola. Post-war period. Deaconship. Social transformation.

\section{Introdução}

Angola é um país da África Austral que sofreu uma terrível guerra civil durante quase 30 anos; foi colônia portuguesa por 500 anos. Em 1961, começou a guerra de libertação colonial, a qual terminou em 1974. Na sequência, três movimentos de libertação denominados Frente Nacional de Libertação de Angola (FNLA), Movimento Popular de Angola (MPLA), e União Nacional para a Independência de Angola (UNITA) entraram em choque entre si e começaram uma terrível guerra civil, que terminou em 2002.

No entanto, no período pós-guerra, vários desafios se apresentam. Diante desses desafios, este artigo tem como objetivo refletir sobre o papel da igreja angolana na transformação social do país em um contexto de pós-guerra civil (2002 ao atual momento). Em um país multiétnico que vive uma situação de pós-guerra, qual seria o papel da igreja? Ela pode ser um agente de transformação social? Como o evangelho pode proporcionar esperança a um povo ferido? Deveria, a igreja, responsabilizar-se pela tarefa de transformadora social? A tarefa de recuperação social seria inerente ao Estado, ocupandose, a igreja, dos aspectos "espirituais" da população?

Vários questionamentos se levantam, pois a igreja não é uma entidade isolada do mundo, ela está nele e diante de todas as situações ela precisa contribuir com a transformação da sociedade. Acreditamos que a igreja tem algo a dizer e a fazer, e que ela não deve fugir do seu papel na transformação da sociedade. E o contexto vivenciado pelos angolanos carece não só de uma intervenção do Estado, mas também de todas as instituições que constituem a sociedade, e a igreja é uma delas. Ela tem, em seu evangelho, uma mensagem de paz, consolo, e um grito por justiça.

Observamos nos sermões de Jesus que o reino de Deus é para aqueles que têm sede de justiça, para os pobres de espírito; vemo-lo, em sua missão, curando e libertando o povo de todas as estruturas de opressão. Levando em consideração isso, vamos refletir sobre o papel da transformação social da igreja angolana no pós-guerra, começando por 
refletir sobre as raízes do conflito, as características do povo de Angola, a postura da igreja e as consequências desse terrível conflito.

\section{A guerra civil em Angola: raízes e consequências}

As raízes da guerra e os povos de Angola

As guerras na África possuem raízes distintas e profundas. E para entendê-las é necessário se aprofundar nos problemas que as geram. O caso de Angola não é diferente. Para entendermos a guerra civil angolana é necessário entender quais são os povos que constituem essa grande nação.

Os povos de origem bantu constituem a grande maioria do povo angolano e descendem das grandes migrações dos bantu ${ }^{1}$ ocidentais e meridionais. ${ }^{2}$ Em Angola, eles estão divididos em aproximadamente 100 grupos. $^{3}$ Dada a limitação do trabalho, mencionaremos apenas três grupos que nos ajudam a compreender as raízes do conflito, com destaque para os bacongos, ${ }^{4}$ ovimbundos ${ }^{5}$ e ambundus. ${ }^{6}$ Deles vieram os três grandes líderes, tanto da guerra de libertação colonial quanto da guerra civil subsequente.

Dos bacongos surge a Frente Nacional de Libertação de Angola (FNLA), ${ }^{7}$ partido que teve como líder Holden Roberto (1923-2007); dos ambundus surgiu o Movimento Popular de Libertação de Angola (MPLA), ${ }^{8}$ com o líder Antônio Agostinho Neto (19221979), e dos ovimbundos surgiu a União Nacional para a Independência Total de Angola (mais conhecida pelo acrônimo UNITA), ${ }^{9}$, liderada por Jonas Malheiro Savimbi (19342002). Como aponta Mateus Chaves, foram esses grupos que se organizaram e mobilizaram outros povos para lutarem ao seu lado, em que cada um invocava a sua razão de lutar. ${ }^{10}$

1 Bantu (forma preferível a "bantos") constituem um grupo etnolinguístico localizado principalmente na África Subsaariana e que engloba cerca de 400 subgrupos étnicos diferentes.

2 Cf. CHAVES, Mateus J. O papel reconciliador da igreja no pós-guerra civil em Angola. Anápolis: Transcultural, 2008. p. 21.

3 Cf. CHAVES, 2008, p. 21.

4 Os bacongos são uma etnia bantu que vive há séculos na região Norte de Angola e em boa parte do Congo. Em Angola, são o terceiro maior grupo étnico.

5 Ovimbundos são uma etnia bantu que ocupa hoje o planalto central de Angola e a faixa costeira adjacente, eles são o maior grupo étnico.

6 Os ambundus são o povo dominante na região da capital angolana e no leste do país, sua língua é o kimbundu, e são o segundo maior grupo étnico.

7 FNLA é um movimento político fundado em 1954, Desde 1991, é um partido político cuja importância tem vindo a diminuir drasticamente, em função dos seus fracos resultados nas eleições legislativas de 1992, 2008 e 2012.

8 MPLA é um partido político de Angola que governa o país desde sua independência de Portugal em 1975.

9 UNITA, fundado em 1966, é o segundo maior partido de Angola, sendo também o maior partido de oposição do país.

10 Cf. CHAVES, 2008, p. 29. 
Ao analisar as causas desse terrível conflito entre irmãos, conseguimos perceber que, além das divergências políticas, fatores como o tribalismo, regionalismo e a superioridade de uns para com os outros foram relevantes para o aumento da tensão. Existiam termos pejorativos que os grupos atribuíam uns para os outros, como o caso dos ambundus, que consideravam o povo do centro como pessoas de mão de obra barata, tratando-os de "bailundos", termo que se tornou pejorativo, significando "homem do centro, mão de obra barata", inferiorizando, assim, os ovimbundos. O que tornava os ambundus "culus", gente que manda, que chefia, sentindo-se, assim, superiores aos "bailundos", como aponta Mateus Chaves:

Durante a campanha eleitoral de 1992, não era raro ouvir nos ônibus e táxis em Luanda pessoas dizendo: "se o homem do Bailundo ganhar, se não tivermos armas, pegaremos em catanas. Ele não pode governar aqui, não queremos um Bailundo como presidente". Do outro lado também se ouvia dizer: "nascidos na mesma terra, não aceitamos que uns nasçam para governar e outros para serem governados". ${ }^{11}$

É por essas e outras razões que se dá início ao conflito armado feito por angolanos contra angolanos. Logo após o término da guerra de libertação contra o colonialismo português, em 1974, os movimentos iniciam um conflito armado pelo controle do país. No dia 11 de novembro de 1975, em Luanda, ${ }^{12}$ o Movimento Popular de Libertação de Angola (MPLA) proclama a independência da República Popular de Angola. E seu líder, Agostinho Neto, assume a presidência do país. E Portugal reconhece o Governo do MPLA.

Do mesmo modo, em Nova Lisboa (atual Huambo),13 a FNLA e a UNITA também proclamam a República Democrática de Angola, que a comunidade internacional nunca viria a reconhecer. Diante disso, os eventos sequentes foram de muita tensão, e a guerra civil começa em 1975.14 Com a morte de Agostinho Neto em 1979, José Eduardo dos Santos ${ }^{15}$ é eleito presidente do MPLA e investido, em seguida, nos cargos de presidente da República Popular de Angola e Comandante-em-Chefe das Forças Armadas Populares de Libertação de Angola (FAPLA).

Em setembro de 1992 foram realizadas as eleições e havia paz, o que não durou por muito tempo. Apesar de as Nações Unidas terem certificado que as eleições tinham sido globalmente livres e justas, a UNITA acusou o MPLA de falsear os resultados,

11 CHAVES, 2008, p. 28.

12 Luanda é a capital e a maior cidade de Angola. Localizada na costa do Oceano Atlântico, é também o principal porto e centro econômico do país.

13 Huambo é uma província de Angola. Tem uma população aproximada é de 2.301 .524 habitantes de etnia predominantemente umbundo.

14 SAMPAIO, Madalena, Cronologia: 1974-2002: das independências ao fim da guerra em Moçambique e Angola. Disponível em: <http://www.dw.com/pt/cronologia-1974-2002-das-independencias-ao-fim-daGuerra-Angola-Moçambique>. Acesso em: 31 ago. 2015.

15 José Eduardo dos Santos é um engenheiro e político angolano. É presidente do MPLA e presidente da República de Angola desde 21 de setembro de 1979. 
remobilizou as suas forças e retomou a ofensiva no final de 1992,16 retomando os conflitos, os quais terminam no dia 4 de abril de 2002 com a assinatura do acordo de Luanda entre o governo MPLA e a UNITA.

As duas formações políticas com mais influência no país pousaram as armas, pondo, assim, fim a 27 anos de guerra civil. Poucas vezes na história a morte de um líder numa guerra civil teve um efeito tão decisivo e imediato. Com efeito, a morte de Jonas Savimbi significou o fim do conflito. ${ }^{17}$ Entretanto, o pós-guerra surge com muitas consequências e vários desafios.

As consequências da guerra civil e os desafios sociais no pós-guerra

O calar das armas chegou, mas o legado deixado pela guerra convive com cada angolano. As mortes, a destruição das infraestruturas, o desemprego, os órfãos, as viúvas, os mutilados e outros males enfermam a sociedade angolana. Diante disso, as estatísticas seriam insuficientes para descrever o tamanho da destruição e, no caso de Angola, temos que nos contentar com meras estimativas. ${ }^{18}$

Segundo Mateus Chaves, a verdade é que dificilmente se encontrara um angolano que, direta ou indiretamente, não tenha perdido pelo menos um membro de sua família nessa guerra. ${ }^{19}$ Realmente, todos foram afetados por esse conflito, o que proporciona lembranças que remetem a um momento específico de dor vivenciado por todos. Como esta história, do senhor Chavala: "meu pai e minha mãe foram mortos juntos, meu filho morreu na tropa, minha esposa morreu num ataque, meu irmão morreu de tuberculose por falta de medicamentos e eu perdi uma perna". ${ }^{20}$ Outra senhora conta: "levaram o meu marido e ele nunca mais voltou, o meu filho foi à tropa e também não voltou". ${ }^{21}$ Histórias como essas são comuns no seio do povo e refletem a desgraça causada pela guerra que destruiu o país em todos os níveis.

O país, que tinha autossuficiência alimentar, passou a ser um dos países mais pobres do mundo; o Gigante Africano adormeceu e a pobreza foi agravada pelo longo período de guerra, o que trouxe e traz sérias consequências humanitárias. ${ }^{22}$ Consequências que estão presentes também na educação. Muitas são as crianças que se encontram fora do sistema de ensino e um elevado número de jovens e adultos ainda são analfabetos.

A grande quantidade de órfãos e viúvas também é marca do terrível conflito que afetou o país. Estima-se que há trinta mil órfãos de guerra. Diante desse precário cenário,

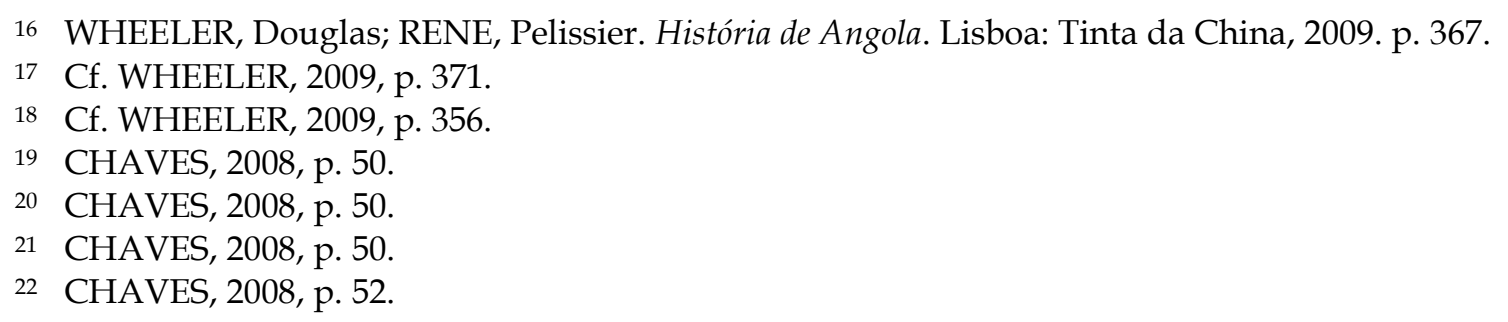


uma das sequelas deixadas pela guerra que se destaca é a pobreza; ela é um fenômeno presente na vida dos Angolanos.

A pobreza é generalizada em Angola e foi agravada pelo prolongado período de guerra civil, o que gerou várias consequências humanitárias. Ela revela-se através dos baixos e persistentes indicadores sociais em setores como saúde, educação, nutrição, água e saneamento, determinados pelo fraco acesso a serviços sociais básicos. ${ }^{23}$

Em detrimento disso, em 2004, dois anos após o fim do conflito armado, o governo angolano traçou a sua Estratégia de Combate da Pobreza (ECP) com o objetivo de suprimir esse fenômeno do seio da população. O plano aponta a pobreza como a consequência principal e direta da guerra. Visto que ela limitou o acesso da população às áreas de cultivo, aos mercados e destruiu os recursos dos camponeses, isso esvaziou o campo de mão de obra e fez afluir milhares de deslocados para as cidades. ${ }^{24} \mathrm{E}$ o êxodo rural deu origem a vários bairros periurbanos densamente povoados em volta da capital Luanda.

Ao falar da dimensão do conflito armado em Angola, Silvia de Oliveira afirma que:

o processo de destruição em que este país esteve envolvido foi demasiado longo e abrangente. Para além das infraestruturas físicas, foram igualmente destruídos os modos de vida, culturas e identidades, resultando daí uma sociedade fragmentada e dividida. ${ }^{25}$

Fragmentação que não contribui em nada para a nova Angola, visto que, a separação torna o povo frágil.

Outra consequência deixada pela guerra é o desemprego em um contexto de famílias monoparentais, em que a maior parte dos jovens está à procura do primeiro emprego. Mesmo diante dessa precariedade, existem algumas pessoas que têm uma vida minimamente estável e conseguem sonhar com uma geração de Angolanos livres da pobreza. Podemos afirmar isso com base nas palavras de Oliveira:

Os poucos que conseguem criar alguma estabilidade investem tudo o que têm na educação dos filhos, para que esta segunda geração saia da condição de pobreza. Esse investimento na mobilidade social é feito por alguns operários e empregados com alguma escolaridade e rendimento fixo. ${ }^{26}$

É um investimento que eles talvez não possam usufruir dos resultados, mas suas atitudes revelam o desejo de uma geração de pais que sonham com um amanhã diferente

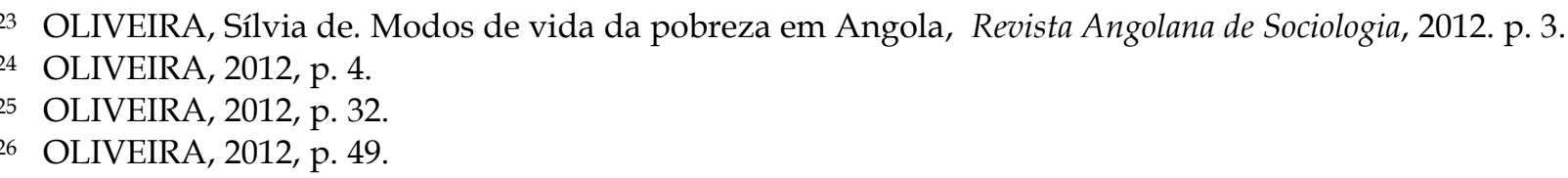


para seus filhos em um país transformado e livre da pobreza. São vários e sérios os desafios na Angola pós-guerra.

Devido à limitação de nossa pesquisa, não nos aprofundaremos, mas, a seguir abordaremos de maneira sucinta a relação entre a igreja e o Estado na Angola, e depois as características da igreja, sua atuação e seu comportamento durante a guerra.

As igrejas na Angola e suas características no pós-guerra

As Igrejas de Angola sofreram várias modificações. No estado colonial, a igreja católica assumia-se como a religião do Estado. A República de Angola é um Estado laico, havendo separação entre o Estado e as igrejas. As religiões são respeitadas e o Estado dá proteção às igrejas, aos lugares e aos objetos de culto, desde que se conformem com as leis do Estado. É visível o aumento na quantidade de confissões religiosas no país, como aponta Fátima Viegas:

Desde a década de oitenta, a sociedade angolana vem assistindo ao crescimento de instituições religiosas provenientes de várias partes, desde África (particularmente da República Democrática do Congo) à Europa, Estados Unidos, Brasil e Ásia (sic). Em simultâneo dá-se o ressurgimento de práticas religiosas locais as quais, na sua maioria, voltadas para os aspectos espirituais e sociais, prometem respostas às necessidades reais da população. ${ }^{27}$

Esse crescimento tem deixado o campo religioso angolano bastante heterogêneo. No campo religioso angolano atual estão presentes as religiões cristãs protestantes, a católica e outras, como os movimentos sincréticos (messiânicos, africanos, religiões não cristãs); as religiões animistas, orientais, muçulmana e as originalmente locais. Ao falar sobre o papel das igrejas ao longo do período de guerra, Tony Neves afirma:

As igrejas (sobretudo, a católica, por ser maioritária) achavam-se no direito de intervir, apoiadas na legitimidade moral que lhes provinha da confiança das populações. Estas sentiam que as igrejas garantiam a esperança, agiam com seriedade, possuíam autoridade moral, ajudavam as populações nos momentos catastróficos, ficavam ao lado das vítimas de Guerra, denunciavam as atrocidades, lançavam apelo aos senhores da guerra para que se sentassem e negociassem uma paz a que o povo tinha direito. ${ }^{28}$

Podemos observar que as igrejas agiram de maneira pacífica, apelando para a paz e para o diálogo. Tiveram um papel catalisador, reunindo vontades, organizando

27 VIEGAS, Fátima. Panorâmica das religiões em Angola Independente (1975-2007). Luanda: INAR, 2008. p. 7.

28 NEVES, Tony. Angola justiça e paz: nas intervenções da Igreja católica, 1989-2002. Luanda: Texto Editores, 2013. p. 164. 
parcerias, provocando reflexão, servindo as vítimas de guerra e os carentes em geral. ${ }^{29}$ Dentre as igrejas, a que maior destaque teve foi a católica. Quanto às instituições religiosas evangélicas, Benedict Schubert destaca o seguinte:

O protestantismo em Angola não conseguiu desempenhar um papel independente e ativo no processo político conflituoso do seu país, mas ficou paralisado. Não era capaz de tirar a força destruidora das suas diferenças internas para transformá-las em elementos de diversidade rica e enriquecedora da unidade; assim, ficou sem defesa, sujeito ao jogo das forças político-militares que lutavam pelo poder. ${ }^{30}$

Para refletirmos sobre o papel da igreja na transformação da sociedade Angolana, utilizaremos o conceito de diaconia, como veremos no próximo capítulo.

\section{A diaconia como ação transformadora}

A transformação de sociedades

Quando falamos de transformação de sociedades, surgem alguns questionamentos: pode a igreja transformar a sociedade? Não seria uma tarefa inerente ao Estado? Mas o que é o Estado senão uma representação da sociedade? E dentre as representações que a compõem não estão os cristãos? Os cristãos deveriam se responsabilizar por essa tarefa? São questões bastante pertinentes e que chamam a atenção da Igreja em Angola.

Como vimos anteriormente, diante da calamidade que assolou o país, as igrejas não cruzaram os braços, simplesmente, mas agiram em prol da paz. Mas ela não pode se satisfazer com pequenas intervenções, sem significativos compromissos ou alta esperança. É necessário um maior engajamento da igreja no mundo, reacendendo o compromisso com a transformação social. Isso é algo desafiador e esperançoso entre o mundo e o reinado de Deus. ${ }^{31}$

Segundo Nordstokke, "pode-se descrever Diaconia como um trabalho prático de mudança para a gente em necessidade". ${ }^{32}$ Ainda, ao falar sobre a missão da Igreja, Armando Gameleira Soares acrescenta que a diaconia é a missão própria da Igreja, isto é, sempre oferecer à sociedade novos sinais concretos da presença e do carinho de Deus, exatamente como fez Jesus em sua atuação em favor dos enfermos, marginalizados e abatidos. Isso pressupõe que o trabalho precisa ser prático para que proporcione mudanças, pois se o reino de Deus está presente, então sua presença deve ser evidente.

29 NEVES, 2013, p. 155.

30 SCHUBERT, Benedict. A guerra e as igrejas: Angola, 1961-1992. Basel: Publishing, 2000. p. 251.

31 OLIVEIRA, David M. Missão, cultura e transformação: desafios para a prática missionária comunicativa. São Leopoldo: Sinodal, 2001. p. 101.

32 NORDSTOKKE, Kjell. Diaconia: fe y servicio en un mundo que sufre. La Paz: Lampara, 1998. p. 81. 
Diante disso, a prática diaconal tem como pretensão antecipar a realidade prometida, ainda que de forma parcial. ${ }^{33} \mathrm{O}$ que significa fazer agora, ainda que em pequena proporção, o que é próprio do reino. ${ }^{34}$ A ação é "agora", ainda que em pequena escala, mas para isso devemos resistir à tentação de separar do evangelho os aspectos espirituais dos materiais, e as dimensões individuais das sociais. A evangelização deve ser integral, pois é assim que a vida de serviço social da igreja se constitui realmente, tendo o serviço integral como parte de seu testemunho. ${ }^{35}$ Testemunho o qual deve proporcionar uma transformação ampla, como nos diz Adiwardana: trazer a transformação por intermédio do evangelho significa redefinir e reintegrar as vidas do povo de Deus dentro do sistema em que vivem e trabalham, reconfigurando seu pensamento e relações sociais com os outros. ${ }^{36}$

É necessário que existam redefinições e ajustes no pensamento do povo de Deus, o que pode gerar transformação. Temos, no evangelho, o poder transformador da sociedade, mas isso se realiza na medida em que a igreja leva em consideração o ser humano, visando a todas as suas necessidades. O relacionamento da igreja com a sociedade não deve se limitar ao âmbito pessoal da fé, mas também a uma ação prática, como exporemos no tópico a seguir.

\section{A diaconia e seu caráter prático}

Existe uma grande preocupação nos meios de reflexão teológica, defendendo-se que não se deve destituir a diaconia do seu caráter prático, pois, segundo Rodolfo Gaede, a insistência nessa questão deve-se à tentativa histórica de espiritualizar todas as tarefas da igreja. $37 \mathrm{O}$ que Gameleira expressa da seguinte maneira: “ora, frequentemente se pensa e se diz que a missão da igreja é espiritual. A tentação que a igreja tem de enfrentar constantemente é a de sentir-se e pensar-se mera encarnação da busca religiosa humana". ${ }^{38}$ Adiel Figueredo complementa, dizendo: "o que temos visto na igreja? Há uma grande preocupação com a evangelização, mas nos esquecemos da beneficência. Dessa maneira não caminhamos" ${ }^{39}$ Ainda, nas palavras de Nordstokke, a igreja que se limita a assuntos espirituais vai ser alienada da realidade da maioria do povo. ${ }^{40}$ E ele acrescenta:

33 OLIVEIRA, 2011, p. 102.

4 DRIVER apud OLIVEIRA, 2001, p. 122.

DRIVER apud OLIVEIRA, 2001, p. 122.

36 ADIWARDANA, Margaretha N. Missionários: preparando-os para perseverar. 2. ed. Londrina: Descoberta, 2001. p. 69.

37 GAEDE NETO, Rodolfo. A diaconia de Jesus: contribuição para a fundamentação teológica da diaconia na América Latina. São Leopoldo: Sinodal, 2011. p. 16.

38 SOARES apud GAEDE NETO, 2011, p. 17.

39 SOARES apud GAEDE NETO, 2011, p. 18.

40 NORDSTOKKE, Kjell (Org.). Diaconia: fé em Ação. São Leopoldo: Sinodal, 1998. p. 3. 
[...] A igreja não pode se limitar apenas ao discurso; o desafio consiste em dar sinais concretos e visíveis de uma compreensão diferente do ser humano e da sociedade civil. Neste sentido, diaconia é denúncia e anúncio de um projeto mais humano e cristão de se relacionar com o outro, com a natureza e a sociedade. ${ }^{41}$

O que o mundo precisa é de uma igreja que não cala sua voz e denuncia as injustiças sociais, que seja a voz dos oprimidos e que anuncie o projeto de Deus de conviver com a sociedade. Porém, sua ação não deve resumir-se a um conjunto de discursos, visto que vivemos em um mundo saturado pelas palavras, seja dos políticos, seja da mídia, até mesmo dos pastores. A supervalorização do discurso tem tornado as igrejas em "agências da palavra", em que o mais importante é o discurso que prioriza o elemento espiritual desconectado das outras dimensões humanas.

Armando Gameleira considera essa prática como "idolatria”, e apela à igreja a não hesitar em denunciar o espiritualismo como corrupção da mensagem cristã, porque, segundo o autor, esconder-se atrás do sagrado é eximir-se da responsabilidade de assumir a tarefa de transformar o mundo. ${ }^{42}$ Essa tarefa demanda mais que discursos e desafia a igreja à práxis, a assumir, assim, a tarefa de transformadora do mundo. Mais adiante discute-se a relação existente entre diaconia, missão e ação social.

\section{Missão e ação social}

Segundo Nordstokke, "historicamente a assistência social tem sido vista como ação paternalista, relacionada a primeiras damas, igrejas ou ainda como uma dádiva do poder público". ${ }^{43} \mathrm{O}$ autor ainda vê tanto na diaconia quanto na assistência social uma finalidade em comum - a vida plena, o bem estar do ser humano, e afirma que somente os fundamentos teóricos, o jeito e a prática, por vezes, são diferentes. Mas que o andar junto pode contribuir com a transformação de estruturas injustas. Ao falar sobre a relação da diaconia e a missão, Nordstokke diz que Jesus é o modelo da missão (cf. João 20.21), e que, através da sua atitude e de seu serviço, não é possível ver a diaconia e a missão como atividades totalmente separadas.

Do mesmo modo, David Mesquiati complementa dizendo que "elas são inseparáveis", 44 e que desde os tempos da igreja apostólica, a missão sempre teve um lado diaconal que vai além de simples iniciativas sociais, ação social e projetos. Segundo o autor, o ponto em comum entre elas é o testemunho da vida e da obra de Jesus, sendo que a vida de Cristo é missionária e revela o seu amor e seu compromisso para com a humanidade. Diante disso, se a ação social perde esse referencial, reduzir-se-á à

41 NORDSTOKKE apud GAEDE NETO, 2011.

42 SOARES apud GAEDE NETO, 2011, p. 18.

43 NORDSTOKKE, 1998, p. 38.

44 OLIVEIRA, 2011, p. 144. 
filantropia. O que seria um total desvio daquilo que é a proposta dos evangelhos, pois podemos dizer que é na missão evangelizadora da igreja como diaconia que está a forma relevante de participação da igreja no mundo. Mas sempre buscando isso com humildade, respeito e tolerância. Assim, a união de ambas protege, a um só tempo, contra uma missão proselitista e uma diaconia que se esgota em mera promoção social. ${ }^{45}$

No relatório escrito durante a consulta internacional (sobre a relação entre evangelização e responsabilidade social) realizada em Grand Rapids sob a presidência de John Stott, ao analisarem as situações e os dons específicos da igreja, os participantes declararam que:

Não é necessário que todas as campanhas evangelísticas sejam acompanhadas por um programa de serviço social simultâneo, de igual modo não é necessário que ao alimentar as pessoas numa região assolada pela seca, primeiro se pregue para elas, pois segundo o provérbio africano, uma barriga vazia não tem ouvidos. ${ }^{46}$

Podemos observar que os participantes entenderam que as pessoas precisam muito mais do que de uma mensagem futurística que promete uma vida nos céus, mas ignora a realidade presente. No referido relatório, os presentes ainda acrescentam: "se a igreja fechar os olhos para o sofrimento, a opressão social, a alienação e a solidão das pessoas, não devia surpreender-se quando elas fecharem os ouvidos à mensagem de salvação eterna" ${ }^{47}$ No entanto, eles assumem que existe um perigo nesse processo de conversão:

Nós estamos conscientes do perigo de produzirmos "conversões interesseiras", ou seja, de garantir novos convertidos em troca dos benefícios materiais que lhes oferecemos. Mas temos de correr esse risco mantendo a nossa integridade e servindo às pessoas com um amor genuíno, sem segundas intenções. Desse modo as nossas ações não serão tentativas de suborno, mas pontes de amor para o mundo. 48

É um risco presente em várias ações de evangelização, porém, por ter em vista o ser humano como um todo, a diaconia respeita esse ser como indivíduo deixando-lhe o direito de ser pessoa sem necessariamente se identificar com a fé. ${ }^{49}$ Diante disso, todo cristão precisa ter a maturidade de servir o outro sem que este precise necessariamente de ir a sua igreja. Porém, a diaconia não deve ser interesseira, mas incondicional levando em consideração a pessoa humana. Podemos ver isso na vida e na ação de Cristo narrada nos

45 NORDSTOKKE, 1998, p. 38.

46 SERIE LAUSANNE 2. Evangelização e responsabilidade social. São Paulo: ABU/Visão Mundial, 1985. p. 19.

47 SERIE LAUSANNE, 1985, p. 21.

48 SERIE LAUSANNE, 1985, p. 21.

49 GAEDE NETO, 2011, p. 25. 
evangelhos, o que passaremos a tratar no tópico a seguir, juntamente com as dimensões da diaconia.

\section{A diaconia em Jesus}

Dimensão profética

É visível a imagem apresentada pelos evangelhos sobre Jesus como o diácono, aquele que veio para servir e não para ser servido, e dar a sua vida pelo mundo, dando exemplo aos seus discípulos. Porém, o fundamento cristológico de diaconia não é igual ao que aconteceu na tradição do movimento diaconal no séc. 19, que tem uma relação forte com o pietismo, no qual temos uma espiritualidade individualista. Em Jesus, ela se expressa de forma ontológica e não apenas em uma dimensão ética, revelando, assim, o modo de ser da igreja, e isso gera consequências importantes para a vida da igreja, visto que indica uma dimensão diaconal que é a identidade da instituição religiosa cristã.

No episódio narrado em Atos 6.1-6, vemos a comunidade primitiva preocupada com a dimensão social da fé, todavia, o que estava em jogo naquele momento não era apenas um sistema melhor de distribuir pão, mas a própria unidade da comunidade, e como isso era o modo de ser da igreja e de fundamental importância para a fé. Assim, o "servir as mesas" tem como objetivo cuidar da qualidade messiânica da comunidade, na qual ninguém passa fome, e onde há distribuição justa. ${ }^{50}$

Alguns autores, como Kjell Nordstokke, dividem a diaconia em algumas dimensões, as quais são, respectivamente, profética, libertadora, ecumênica, ecológica e transformadora. No presente artigo, focaremos na dimensão profética que, para o autor, é imprescindível em um lugar onde a vida está ameaçada, mas vale lembrar que ela, nesse contexto, é expressa em tom de denúncia contra os tipos de opressão e tudo que visa colocar em risco a vida humana. Então, nessa realidade, Deus quer agir através de palavras e de ações, e como diria Gaede Neto, basta! Assim como está não pode continuar. ${ }^{51}$

Na perspectiva de Frei Betto, a diaconia profética no terceiro mundo implica em lutar pelos direitos fundamentais de vida, alimentação, saúde, educação, trabalho, etc., visando construir mulheres e homens novos, o que inclui o serviço da conquista da paz. ${ }^{52}$

Uma paz que, no caso de Angola, não deve ficar restrita ao calar das armas conquistado em 2002, mas precisa alcançar todas as áreas da vida do angolano. Por isso, a igreja angolana deve levantar sua voz profética e anunciar o Reino, denunciando todas as injustiças presentes na vida do cidadão de Angola.

50 NORDSTOKKE, 1998, p. 242.

51 GAEDE NETO, 2011, p. 24.

52 FREI BETTO apud GAEDE NETO, 2011, p. 25. 


\section{Dimensão curadora: o sofrimento como elemento terapêutico}

A segunda dimensão presente na ação diaconal de Jesus que gostaríamos de destacar é a curadora. As escrituras sagradas apresentam o Messias como aquele que vem para servir. Porém, ele também é o servo sofredor e seus sofrimentos são uma fonte de cura para muitos. Podemos constatar isso também nas palavras de Abdruschin Rocha, quando afirma:

Somos informados por Isaías que pelas feridas do Messias nós fomos curados (cf. Is. 53.5). Isso significa que, ao contrário de um cuidado baseado na "força do cuidador", herança da Modernidade Iluminista, somos continuamente cuidados pela fragilidade de Cristo. Portanto, não é mais a força do sujeito a responsável pela cura, mas sua fundamental fraqueza. ${ }^{53}$

Utilizar a fraqueza como fonte de cura é trilhar um caminho diferente e desafiador. Para explicar melhor isso, o autor acrescenta que é necessário utilizar uma abordagem "homeopática", que, segundo ele:

se caracteriza por um cuidado que se expressa também mediante a comunhão nos sofrimentos, o que significaria chorar com os que choram (mais do que enxugar as suas lágrimas); sofrer com os que sofrem (mais do que eliminar o sofrimento); manifestar ao outro nosso quebrantamento (e não apenas querer edificar); não ocultar nossos extravios (melhor do que apenas ofertarmos a salvação). ${ }^{54}$

Realmente, utilizar a fraqueza como elemento curador constitui-se um desafio para a Igreja de Cristo em Angola, pois, diante dos sofrimentos causados pelo conflito armado, sendo ela vítima, ela pode usar de seus ferimentos para curar outros.

O teólogo holandês Henri J. M. Nouwen, em seu livro O sofrimento que cura, apresenta uma lenda extraída do Talmude que conta um diálogo entre o profeta Elias e Rabbi Joshua, quando este estava de pé junto à entrada da caverna de Rabbi Simeron bem Yohai. Conta a lenda que:

Rabbi Joshua pergunta a Elias:

- Quando virá o Messias?

E Elias respondeu:

- Vá e pergunte-lhe você mesmo.

- Onde ele está?

- Sentado junto aos portões da cidade.

- Como poderei reconhecê-lo?

53 ROCHA, Abdruschin Schaeffer. Hermenêtica do cuidado pastoral: lendo textos e pessoas num mundo paradoxal. São Leopoldo: Sinodal/EST, 2012. p. 253.

54 ROCHA, 2012, p. 254. 
- Ele está sentado entre os pobres, coberto de ferimentos. Outros desenfaixam todos os seus ferimentos, e então, enfaixam-nos de novo. Mas ele desenfaixa um por vez e enfaixa-o novamente dizendo para si mesmo: "Talvez eu seja requisitado; se assim for, preciso estar sempre pronto, para não me atrasar nem por um momento". ${ }^{5}$

Nessa história, o Messias enfaixa os seus ferimentos, um por vez, mas sempre em prontidão para que a qualquer momento que ele for requisitado, esteja pronto para atender e não se atrasar. ${ }^{56}$ Ele é um ferido que procura seus ferimentos, porém, ele está preparado para curar os ferimentos dos outros. De maneira análoga, vemos que a igreja, em seu papel terapêutico, deve agir da mesma maneira que o Messias: enquanto ela enfaixa seus ferimentos, deve se engajar na cura dos feridos da comunidade.

\section{Conclusão}

Podemos concluir que os desafios para a igreja em Angola pós-guerra são enormes e ela não pode restringir-se apenas aos assuntos "espirituais", pois cremos que deve haver diaconia enquanto existirem crianças padecendo por falta de comida; idosos abandonados; pais desesperados por não poderem sustentar suas famílias; órfãos; viúvas; e jovens e adultos analfabetos. Na medida em que o clamor por justiça, paz e liberdade ecoar, a Igreja angolana é chamada a engajar-se no anúncio do reino Deus e a apresentar o Reino como uma realidade presente, fazendo de Angola "um prelúdio dos céus", assumindo a forma de servo, devendo, em tudo, subordinar-se a tal propósito. Este serviço pode ser concretizado em várias ações práticas. Por exemplo: as igrejas em Angola podem criar grupos de apoio a enlutados, que seria um grupo de pessoas que se reúne em torno de um mesmo sentimento, que é a dor, onde as pessoas podem chorar o luto pela perda de um ente querido. O grupo ajudará as pessoas enlutadas, viúvas e órfãs a passar por este momento. Isto porque para o enlutado é importante saber que não está sozinho na sua dor e que tem pessoas que o entendem e que tiveram perdas semelhantes.

As igrejas, podem também criar um projeto para o controle e erradicação da Malária. Uma doença que tem sido a causa da morte de muitos angolanos. Ela pode também oferecer cursos profissionalizantes para pessoas desempregadas da igreja e do bairro em que está inserida. Pode engajar-se também na criação de pré-vestibulares gratuitos, que ajudarão jovens e adolescentes a terem acesso à universidade. Os membros das comunidades, professores e não só podem unir-se e criar projetos de reforço escolar para crianças. As igrejas podem também promover momentos de debates, junto com a comunidade, para analisar as dificuldades do bairro e juntos pensar em como contribuir para mudar a realidade em que estão inseridos.

55 NOUWEN, Henri J. M. O sofrimento que cura. 3. ed. São Paulo: Paulinas, 2007. p. 118.

56 NOUWEN, 2007, p. 118. 
Assim, o papel de transformação social da igreja angolana em um contexto pósguerra, em primeiro lugar, deve ser profético. Vale ressaltar que entendemos profecia no sentido de denúncia, e a igreja angolana é convidada a denunciar e a lutar contra todas as injustiças sociais, sempre optando pelos oprimidos. Em segundo lugar, seu papel deve ser terapêutico, cuidando das feridas dos angolanos, sejam espirituais, sejam físicas, chorando com os que choram e dando esperança aos desenganados; transformando cidadãos para uma Angola melhor.

\section{Referências}

ADIWARDANA, Margaretha N. Missionários: preparando-os para perseverar. 2. ed. Londrina: Descoberta, 2001.

CHAVES, Mateus J. O papel reconciliador da igreja no pós-guerra civil em Angola. Anápolis: Transcultural, 2008.

GAEDE NETO, Rodolfo. A diaconia de Jesus: contribuição para a fundamentação teológica da diaconia na América Latina. São Leopoldo: Sinodal, 2011.

NEVES, Tony. Angola justiça e paz: nas intervenções da Igreja católica, 1989-2002. Luanda: Texto Editores, 2013.

NORDSTOKKE, Kjell (Org.). Diaconia: fé em Ação. São Leopoldo: Sinodal, 1998.

. Diaconia: fe y servicio en un mundo que sufre. La Paz: Lampara, 1998.

NOUWEN, Henri J. M. O sofrimento que cura. 3. ed. São Paulo: Paulinas, 2007.

OLIVEIRA, David M. Missão, cultura e transformação: desafios para a prática missionária comunicativa. São Leopoldo: Sinodal, 2001.

OLIVEIRA, Sílvia de. Modos de vida da pobreza em Angola, Revista Angolana de Sociologia, 2012.

ROCHA, Abdruschin Schaeffer. Hermenêutica do cuidado pastoral: lendo textos e pessoas num mundo paradoxal. São Leopoldo: Sinodal/EST, 2012.

SAMPAIO, Madalena, Cronologia: 1974-2002: das independências ao fim da guerra em Moçambique e Angola. Disponível em: <http:/ / www.dw.com/pt/cronologia-1974-2002das-independencias-ao-fim-da-Guerra-Angola-Moçambique>. Acesso em: 31 ago. 2015.

SCHUBERT, Benedict. A guerra e as igrejas: Angola, 1961-1992. Basel: Publishing, 2000.

SERIE LAUSANNE 2. Evangelização e responsabilidade social. São Paulo: ABU/Visão Mundial, 1985. 
VIEGAS, Fátima. Panorâmica das religiões em Angola Independente (1975-2007). Luanda:

INAR, 2008.

WHEELER, Douglas; RENE, Pelissier. História de Angola. Lisboa: Tinta da China, 2009. 